\title{
Construction Management of EVH \& UVH Transmission Lines A Practical Guide
}

\author{
Biswanath Sahu \\ B.Sc. Engg. PGDM (HRM), PGDM ( E\&E), Gmpe(Iim-I) \\ Country:- India
}

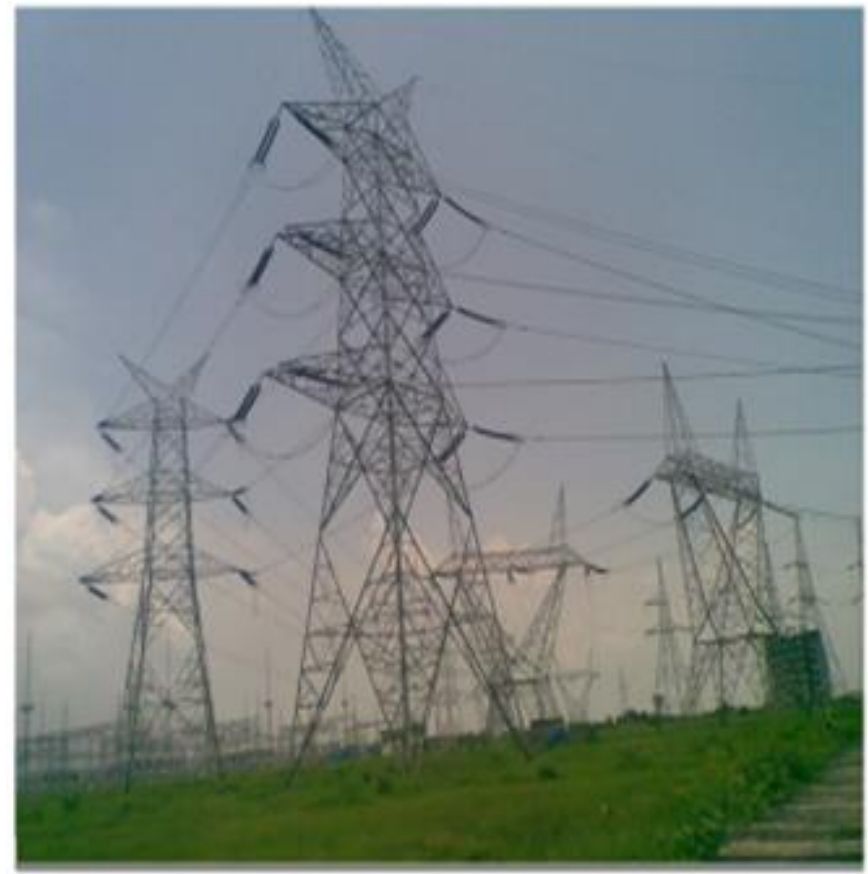

\begin{abstract}
Generation projects are generally located in areas nearer to availability of inputs required for power generation such as water, coal, approach roads and having rail transport facilities. The load centers are at different locations depending its own convenience load requirement. Hence there is necessity of transmission of bulk power from generation sites to load or consumer points.
\end{abstract}

Hence the utility of power transmission through EHV/UHV transmission lines. Further for transmission of bulk power from one region of country to another region also warrants establishment of Transmission lines. The technical as well as social and commercial criteria are very important while construction and erection of EHV and UHV transmission lines. These issues are of public as well as organization importance and hence efforts have been made in this presentation to elaborate in detail.
Keywords:- The key words in this paper are Right of Way (ROW); Crop, Tree and land compensation; clearances; Government stipulations; commercial issues, Farmer issues; soil conditions; Forest, Highways, Rly ways approvals etc.

\section{INTRODUCTION}

- Power supply has become essential for day to day life sustenance in a society.

- Global climatic developments demand supply of reliable and quality power at minimum cost having minimum impact on environment.

- It is $s$ a tough challenge to maintain balance among mutually opposing issues such as reliability in bulk power transmission, maintenance of environmental sustainability with economic efficiency.

- The above tricky Situations can be tackled by focusing our action in the following areas.

Adopting innovative and advanced technologies in areas of power transmission suchas:

- HVDC (High voltage Direct current) Power Transmission System. 
- FACTs (Flexible AC Power Transmission System) by make use of Series and Shunt capacitors.

- SMART Grids. Exploring wide usage of Super conductors in Transmission Sectors.

- Transmitting power at Ultra high Voltage level and reducing comparative transmission losses.

\section{$>$ Series \& Shunt Compensation}

- FACTS for series compensation modify line impedance

- $\mathrm{X}$ is decreased so as to increase the transmittable active power.

- $\mathrm{P}=\mathrm{V}$ Square/X-Xc (Sin delta)

- In Shunt compensation reactive current is injected into line tomaintain voltage magnitude.

- Transmittable active power is increased.

- $\mathrm{P}=2 \mathrm{~V}$ square/XSin(delta/2)

- Power flow in case of EHVAC \&UHVAC $\mathrm{P}=0.5(\mathrm{Vs} . \mathrm{Vr}) / \mathrm{xl}, \mathrm{Vs}=$ Sending end voltage \& $\mathrm{Vr}=\mathrm{Receiving}$ end voltage.

- $(\mathrm{xl}$ is reactance of line per $\mathrm{km} \&$ per phase. $) \& \mathrm{xl} / \mathrm{Km}$ of line $400 \mathrm{KV}-0.327,765 \mathrm{KV}-0.272,1000 \& 1200 \mathrm{KV}-0.231$

\section{> HVDC Transmissionlines}

- HVDC also called electrical super highway used for bulk transmission of electrical power.

- Long distance power transmission may be less expensive \& have lower losses.

- $1100 \mathrm{KV}$ link in china completed in 2019 over distance of $3300 \mathrm{~km}$ with power flow $12 \mathrm{GW}$.

- HVDC allows power transmission between unsynchronized Ac transmission systems.

- HVDC allows power flow between grids running in different frequencies such as $50 \mathrm{~Hz} \& 60 \mathrm{~Hz}$ and improves stability \& economy of each grid.

- Longest HVDC link Rio in Brazil +600KV bipolar 2375 Km having power flow $3150 \mathrm{MW}$.

- HVDC have low resistive loss (3\% ) which is 30 to $40 \%$ less than $\mathrm{AC}$ due to low current ,less conductor, no skin effect.

- Disadvantage with HVDC are conversion, control, availability \& maintenance.

- HVDC CB are difficult to build because of arching in comparison toAC because of voltage of inversion in AC.

\section{> TYPESOFHVDC}

- Monopole- Between two AC systems one DC Line with earth return.

- Bipolar-Two conductors are used in opposite polarity hence negligible earth current.

- Back to Back- It is a plant in which both converters are in the same building. (DC line length is as short as possible) It is used for coupling of grids of different frequencies, different phase relationship or both.

- Multi-terminal system- can be series, parallel or hybrid.

\section{SMART GRID}

- Smart grid is an Electrical grid which includes a variety of operations \& energy measures such as smart meters, smart appliances, renewable \& energy efficient resources.

- Electronic power conditioning \& control of the production and distribution of electricity are important aspect of smart grid.

- It makes use of state estimation that improves fault detection and self-healing \& ensures reliable supply of electricity and reduced vulnerability to natural disasters or attack.

- It ensures Flexibility in Network topology.

- Ensures efficiency of energy infrastructure including DSM

\section{> ULTRA HIGH VOLTAGE TRANSMISSION:}

- Operating at greater than $800 \mathrm{KV}$ to expand T\&D capacity and reduce losses.

- $1150 \mathrm{KV}$ UHVAC in Russia $2362 \mathrm{Km}$ length line, $1000 \mathrm{KV}$ UHVAC in Japan. In China $1000 \mathrm{KV}$ UHVAC and 800KVUHVDC are in operation.

- HV-33KV, EHV-110-400KV and UHV- 800KV\& above.

- Allows Generation plants closer to fuel source and away from population centers.

- Ability to integrate widely dispersed renewable power sources into a national distribution network.

- Biswanath chariali (Assam)-Agra 800KV UHVDC capacity 6000MW, length $1728 \mathrm{Kms}$ To be commissioned

1200KV UHVAC link at Testing Station Bina under testing.

> Technology \& System advancement

- Introduction of 400KV lines in 1977

- Beginning of $765 \mathrm{KV}$ lines in 2000

- Introduction of HVDC Back to Back-1989\& HVDC Bipole-1990

- Introduction of Electricity new Act-2003 \& Open Access-2004

\section{FIELDWORKSFORCONSTRUCTIONOF TRANSMISSIONLINES}

* Survey

A ReconnaissanceSurvey:

- shortestroutefrom dispatchendtoreceivingendoflineistobe drawnonSurveyOfIndiaMapwhichiscalled"BeeLine"

- Walk down survey is to be carried out along the line wrt the BEE line approaching all possible approaches to line.

- Close to BEE line tentative line is to be marked avoiding passing of line through villages, towns, unapproachable hillocks, forests, air ports, Rly stations.

- While walking various crossings such as unavoidable forests, Rail tracks, Rivers, power lines etc.\& approximate distances from airport Station major villages $\&$ towns are marked and noted.

- Earth resistivity is taken wherever soil strata changes. ( $\mathrm{SR}=2 \mathrm{pieSR}$ )

$\mathrm{S}=50 \mathrm{mtr}$ (4 Electrode methods) 
- In line with Sec 164 of E. Act-2003 Gazette Notification is published in State Gazette and a copy of notification is published in local newspapers.

- Communication to be given to state Highway, National High way, Rail ways, PTCC authority, forest and airport authorities and Transco's regarding power line crossings.

\section{PRELIMINARY SURVEY(ROUTEALIGNENT)}

- Actual survey with theodolite or total station is carried out along the Tentative route marked during reconnaissance survey.

- Fixing of angle tower locations done.

- Finalization of crossing locations (River, Power lines, Rail way tracks SHW\& NHW, P\&T lines etc.

- Concrete pillars of size $200 \times 200 \times 300 \mathrm{~mm}$ are fixed at angle locations $50 \mathrm{~mm}$ below ground.

- Wooden pegs of size 50x50x150mm are embedded on ground along the line in between angle locations at $750 \mathrm{mtrs}$ intervals at prominent places.

- Direction pegs are marked for angle \&section tower locations.

- Earth resistivity along the route is taken.

\section{$>$ APPROVALS SOUGHT}

- Approval from local forest authority to carry out survey and trimming some trees if required.

- Proposal in prescribed format to be submitted to forest dept. For obtaining approval to lay line inside forest land.

- Route approval from internal Authority.

- Submission of route with soil data to PTCC, RLY, AVIATION

(if tower height is more than 45 meters), chief Electrical Inspector of state \& center, Transco for power line crossings, SHW\& NHW for road crossings, etc.

\section{TECHNICAL DETAILS}

* Type of Towers:

There are four types of Towers depending upon angle of deviation.

A type upto2 degree, B-2 to 15, C-15to 30\&D-upto 60 and DEAD END(DE)

Section Towers: without angle

Any angle towers after every 15 spans or $5 \mathrm{Kms}$ whichever is less for plain areas and 10 spans or $03 \mathrm{Kms}$ in hill areas.

Basic span: Distance between towers

400KV-400mtrs,220KV-350mtrs, 132KV-335mtrs.

River crossings \& road crossings span is $300 \mathrm{mtrs}$ or $80 \%$ of normal.

Rail track, NH \& P\&T line crossings angle 90 deg and angle tower on either sides or distance of towers $\mathrm{H}+6$ where $\mathrm{H}$ is tower height.

\section{> DETAILED SURVEY\&PLOTING OF PROFILE}

- Levels of ground profile along route is taken at $30 \mathrm{mtrs} \&$ wherever terrain changes.

- Levels are marked on profile sheet taking starting point as RL100

- Detail levels of all crossings taken.

- Heights of all salient features $50 \mathrm{mtrs}$ on either side of line are taken.

- Profile is plotted in $1 \mathrm{cmsq}$ graph sheet taking $1 \mathrm{~cm}=20 \mathrm{mtrs}$ Horizontal \& $1 \mathrm{~cm}=2 \mathrm{mtr}$ in vertical.

- Profile shows longitudinal as well as cross section view of line.

- All crossings with angle of crossing, heights are plotted in profile.

\section{TOWERSPOTTING\&TOWERSCHEDULE}

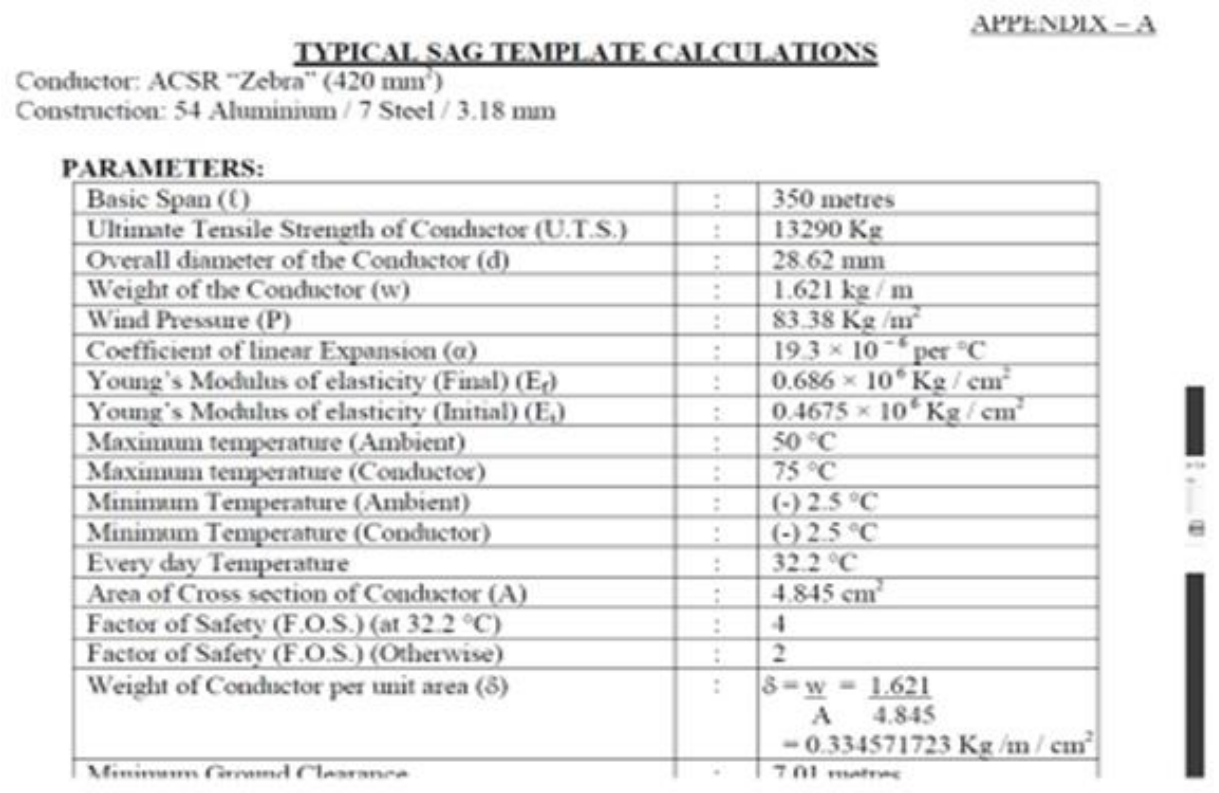

Fig 1 
- Sag Template is prepared specific to line voltage and conductor used.

- Template is prepared as per I E Rule taking care of vertical\& wind load and is approved by competent authority.

- The following set of Parabolic curves are drawn on a transparent celluloid or acrylic clear sheet:

- 1 Cold or uplift curve-sag at minimum temp $-2.5 \mathrm{deg}$ \&still wind.

- 2 Hot or max sag curve-Max temp \&still wind.

- 3 Ground clearance curves.4.Tower footing curve.

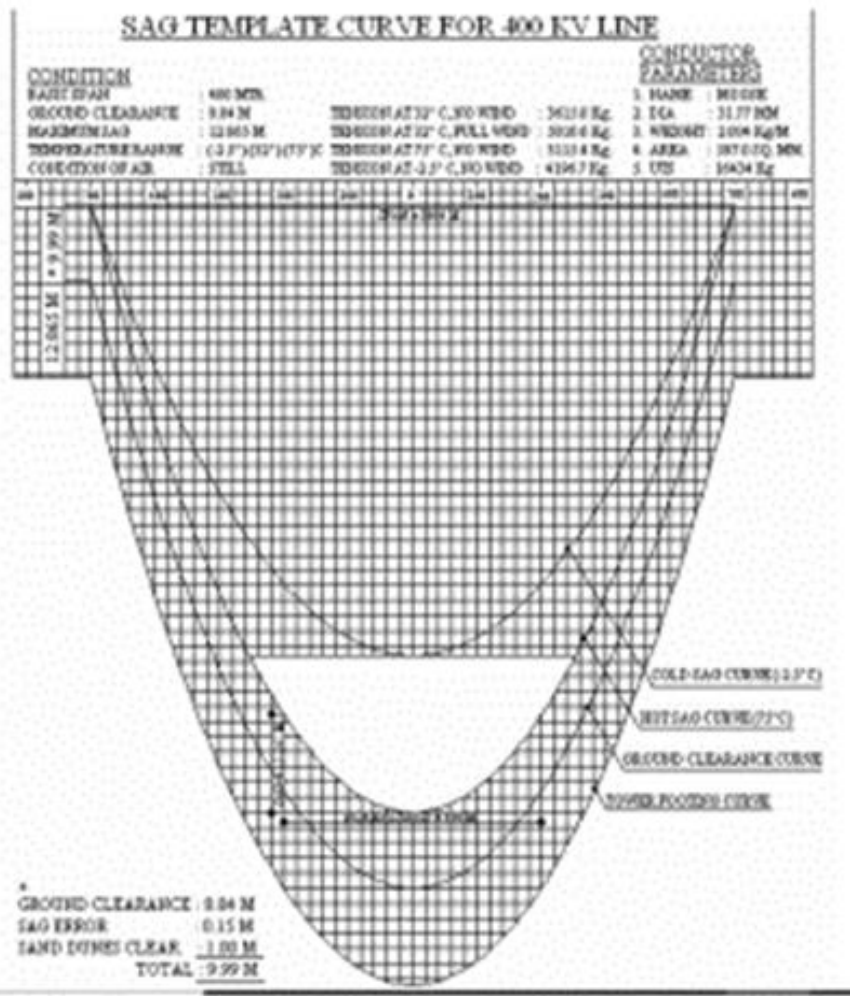

Fig 2

$>$ CLEARANCE DETAILS

- As per I E Rule -77 the Ground clearances are:

- $132 \mathrm{KV}-6.10 \mathrm{mtrs}$,

- $220 \mathrm{KV}-7.00 \mathrm{mtrs}$

- $400 \mathrm{KV}-8.84 \mathrm{mtrs}$

- $800 \mathrm{KV}-12.40 \mathrm{mtrs}$

- Rail way crossings (above rail level):

$\checkmark$ 66KV-132KV-14.60mtrs\&132-220KV-15.40mtrs

$\checkmark$ 220-400 KV-17.90\&400-500KV-19.30mtrs500KV800KV-23.40mtrs.

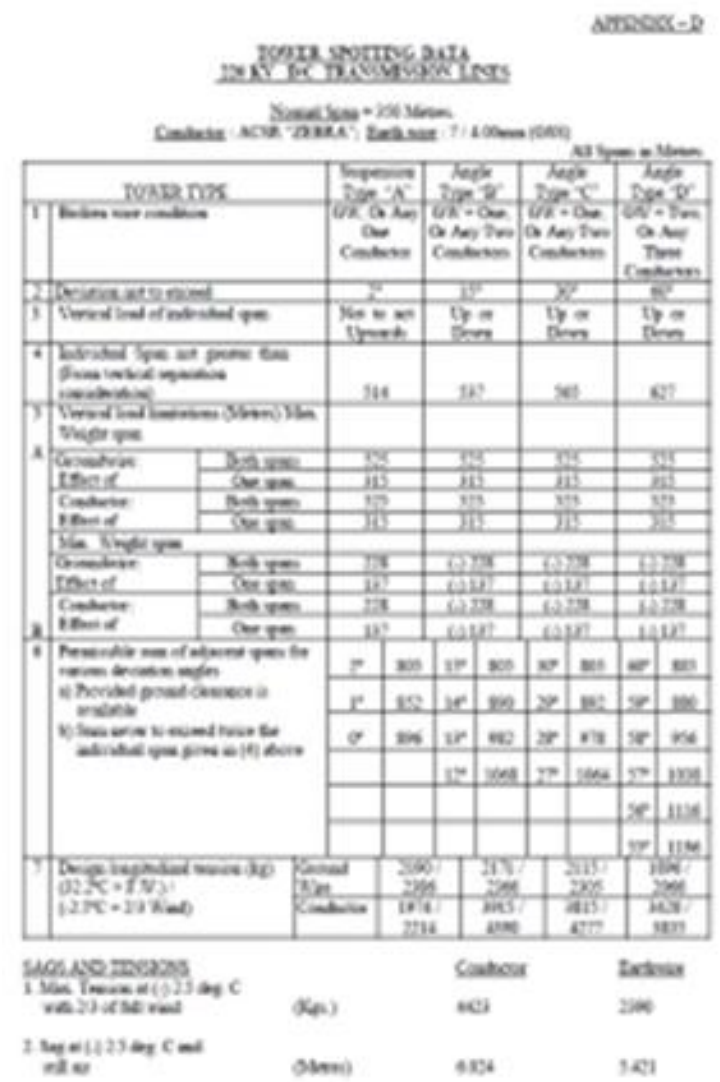

Fig 3

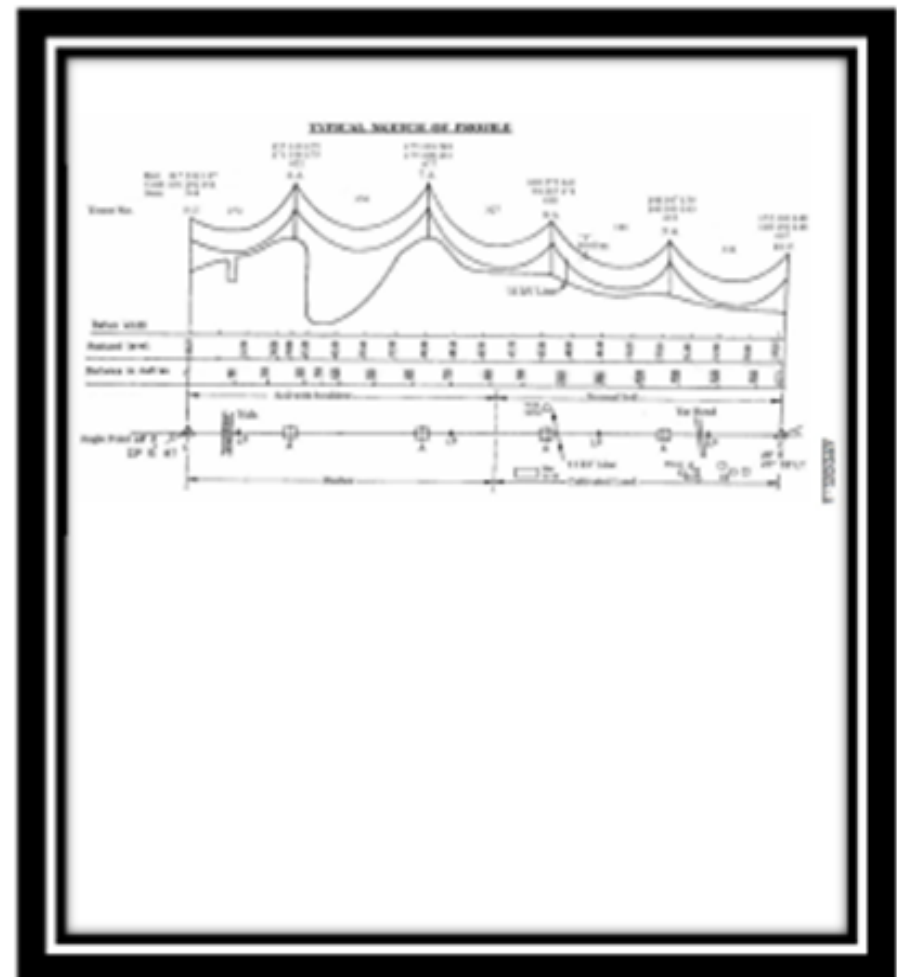

Fig 4:- Profile 
ISSN No:-2456-2165

POWER LINE TOPOWER LINE CLEARANCE

\begin{tabular}{|cc|c|c|c|c|}
\hline & $132 \mathrm{KV}$ & $220 \mathrm{KV}$ & $400 \mathrm{KV}$ & $800 \mathrm{KV}$ \\
\hline$\bullet$ & $11 \mathrm{KV}-66 \mathrm{KV}$ & 3.05 & 4.58 & 5.49 & 7.94 \\
\hline$\bullet$ & $132 \mathrm{KV}$ & 3.05 & 4.58 & 5.49 & 7.94 \\
\hline$\bullet$ & $220 \mathrm{KV}$ & 4.58 & 4.58 & 5.49 & 794 \\
\hline$\bullet$ & $400 \mathrm{KV}$ & 5.49 & 5.49 & 5.49 & 7.94 \\
\hline$\bullet$ & $800 \mathrm{KV}$ & 7.94 & 7.94 & 7.94 & 7.94 \\
\hline
\end{tabular}

Table 1

\section{OTHERCLERANCES}

- Minimum Clearance between Conductor \& Tree

- $\quad 400 \mathrm{KV}-5.5 \mathrm{mtr}$

- $\quad, 500 \mathrm{KV}-7.4 \mathrm{mtr}$,

- $765 \mathrm{KV}-9.0 \mathrm{mtr}$

- $\quad 800 \mathrm{KV}-10.6 \mathrm{mtrs}$

- $1200 \mathrm{KV}-13.0 \mathrm{mtr}$

- Clearance Between Lowest cross arm and Traction Mast:

- $\quad 400 \mathrm{KV}-9.71 \mathrm{mtrs}$

- $\quad 500 \mathrm{KV}-11.45 \mathrm{mtrs}$

- $\quad 800 \mathrm{KV}-16.67 \mathrm{mtrs}$

\section{OTHER CRITERIAS}

- To meet ground clearance tower with extension or reduced span whichever is economical is to be used.

- Span should be as close to as design span.

- Power line crossings double suspension and tension Insulators used.

- River crossings:

- Non-Navigated- clearance 3mtrs from High Flood Level.

- Navigated-approval from authority is required.

- Road crossings: NH \& Major SH- span 250mtrs(double tension \& suspension insulators for clearance \& ODC consignment.

\section{SPAN \&SAG}

- Normal span-Design span

- Wind Span-On either side of a tower 50\% spans

- Weight span- Tower either side lowest conductor point distance.

- Max Sag $=(1$ square d q $) / 8 f \quad$ where l=length of conductor $=$ W/A (weight $/ \mathrm{mtr}$ of conductor, A-area of cross section) $\mathrm{q}=$ Loading factor $=01$ for still wind. $\mathrm{F}=$ Stress on conductor cross section.

- Sag at basic span/ sag at any $\operatorname{span=~Basic~Span~}$ square/Span Square

- From profile Location wise tower schedule that is no of different towers and extensions are prepared.

C CHECK SURVEY(Location marking on ground) \& stub setting

- Location of angle towers and suspension towers are marked on ground.

- Direction pegs are fixed on ground for angle towers.

- During stub setting again location points are checked and confirmed.

- Pit marking for trial pit excavation to classify soil is done.

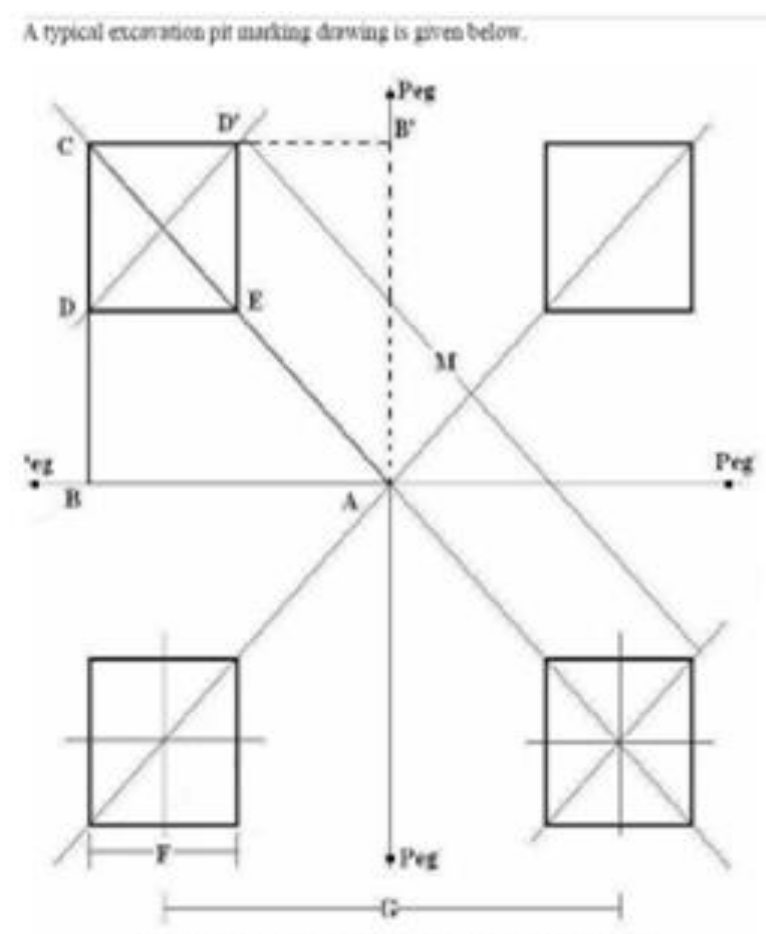

EXCAVATION MARKING CHART

Fig 5

- Stub setting is done with stub template.

- Stub and other accessories required along with concretingmaterials are to be made available at site.

\section{Excavation \& Pit Marking}

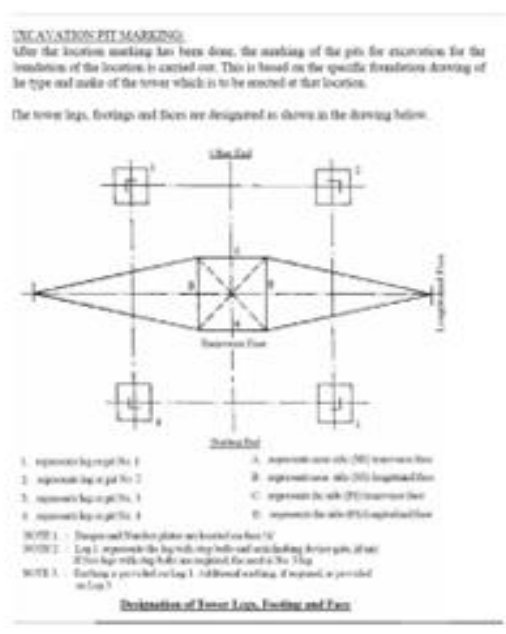

Fig 6

\section{RIGHT OF WAY(PowerCorridor)}

- Trees coming in Power corridor need to be numbered. A statement detailing height, girth and nature\& yield to be prepared with owner details for assessing compensation.

- ROW for 132 KV$15 \times 2=30 \mathrm{mtr}, 220 \mathrm{KV}=35 \mathrm{mtr}, 400 \mathrm{KV}=52 \mathrm{mtr} \quad \& 765$ $\mathrm{KV}=85 \mathrm{mtrs}$.

- In forest areas the ROW required is: 
- $11 \mathrm{KV}-07 \mathrm{mtr}, 33 \mathrm{KV}-15,66 \mathrm{KV}-18,110 \mathrm{KV}-22,132 \mathrm{KV}$ $27,220 \mathrm{KV}-35$

- 400KVS/c-46, D/C -46mtr,500KV-52,765KV-S/C64,D/C-67

- $800 \mathrm{KV}-69 \mathrm{mtr} \& 1200 \mathrm{KV}-89 \mathrm{mtrs}$

> PAYMENT OF COMPENSATION

- After route is finalised ownership of land and crop and trees affected or going to be affected during foundation, tower erection \& stringing need to be got certified by revenue officials (Patwari, Tahsildar)

- Notices need to be issued to the owners that they are to be suitably compensated as assessed, certified and approved by revenuedept.

- Statement for Damaged crops \& trees to be submitted to revenue/Horticulture/forest dept. for finalisation of amount.

- For crop \&tree as many times these are damaged to be compensated.

- For land for tower \& overhead conductor as decided by collector to be compensated.

- Foundations are classified as:

- For Normal soil-Dry, Wet, Partially submersed, Fully submerged.

- This is the most difficult part of Execution in Transmission lineworks.

\section{SOIL CLASSIFICATION}

- SOIL at tower location is classified as:

- Normal soil-(If the soil is no other types given below)

- Black Cotton

- Fissured Rock

- Hard Rock

- Sandy soil

\section{FOUNDATIONCLASSIFICATION}

- Dry- soil is normal, water is not met up to bottom of pit at $3.0 \mathrm{mtr}$ in worst season.

- Wet-Soil is normal, water met on surface like paddy field after that no water up to $1.5 \mathrm{mtr}$ from GL.

- PS-Soil normal, water met with in 0.75 to $1.5 \mathrm{mtr}$ from GL

- FS-Soil normal, water met with in GL to $0.75 \mathrm{mtr}$

- WBC-soil is Black cotton (at least $1.0 \mathrm{mtr}$ from bottom of pit)

- FR-If soil is Fissured rock, marram (at least $1.0 \mathrm{mtr}$ from bottom of foundation. If water within $1.5 \mathrm{mtr}$ from GL special foundation.

- HR- Soil HR at least $1.0 \mathrm{mtr}$ from bottom. Sandy soilspecial.

\section{TOWER ERRECTION}

\section{TOWER ERECTION}

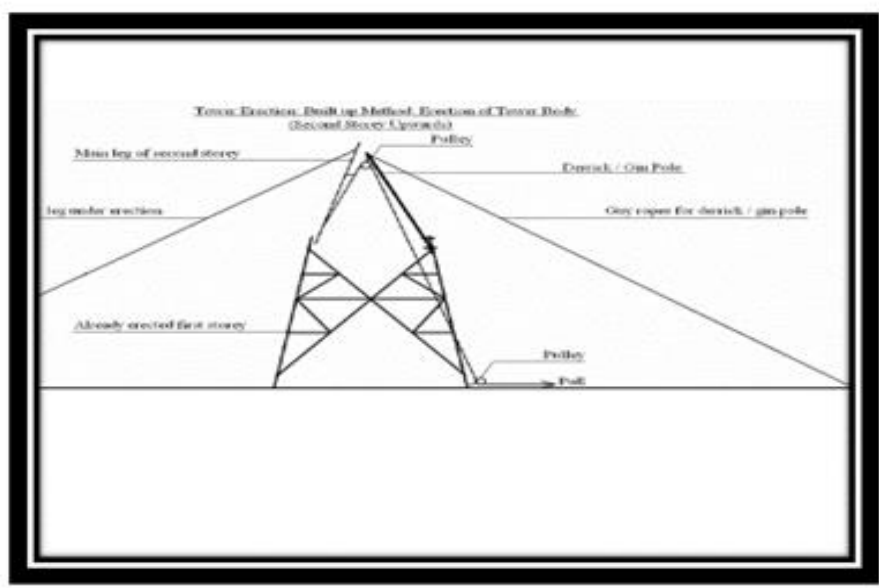

Fig 7

Methods of Tower erection:

- 1 Built up method or piece method by Deric \& Gi pole( widely used)

- Section wise by crane.

- Ground assembly and total tower lifting by crane-Rarely used, for small height towers feasible.

- It is a very specialized and skilled job can be done by experienced gangs.

\section{TOWER ERECTION}

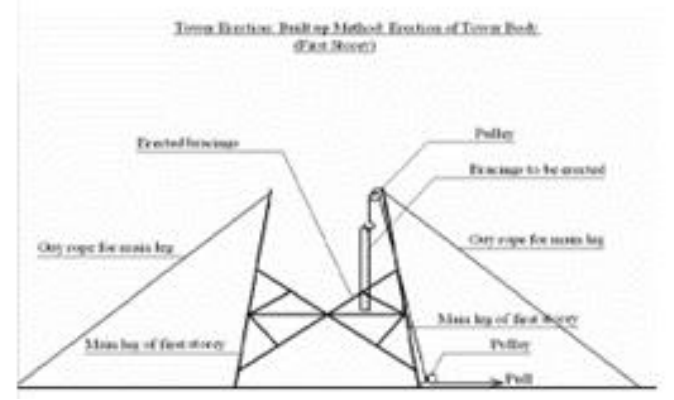

Fig 8

- Proper supervision to ensure safety of people on job is essential.

- Tack welding at least up to bottom cross arm \& applying cold galvanized paint is required. 


\section{STRINGING ARRANGEMENT:}

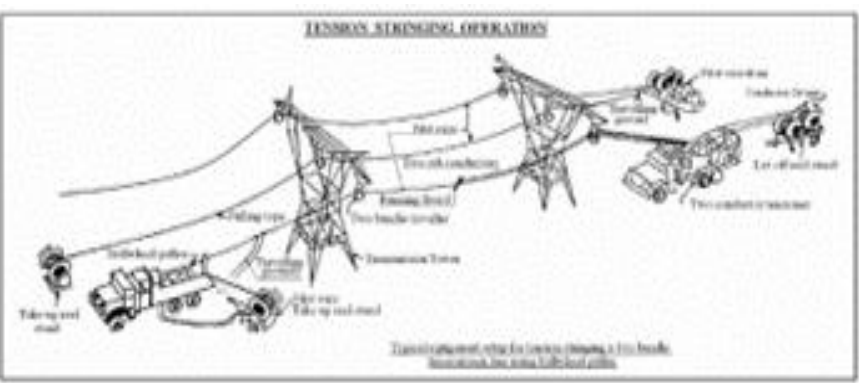

- The following are activities:

- Checking of Insulators and other line hardware \& accessories.

- Fixing of rollers/Travelers, running blocks, D-sackal, yoke plates.

- All DE and angle towers are to be provided stay/anchors.

- Double stay for cross arms\& single for peak to be given.

Fig 9

\section{Pulley Fixing \& Tensioning the Line}

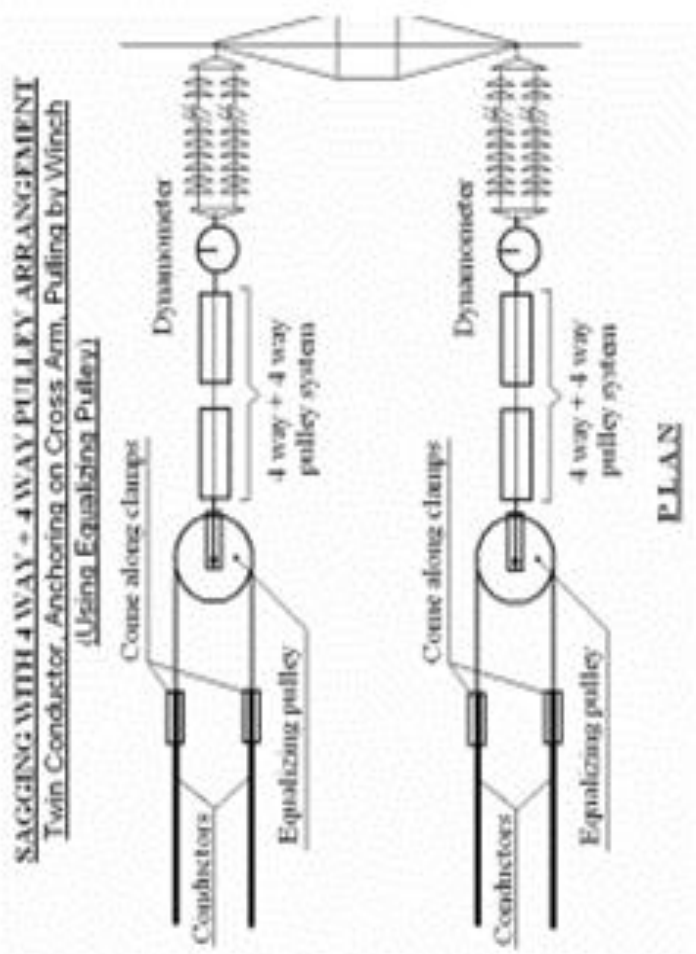

Fig 10

- Up to $220 \mathrm{KV}$ Tractors used for pulleying, $400 \mathrm{Kv}$ Tensioner\& pullers.

- Rough sagging done first with winch,4way pulley/Equalizingpulley\& dynamometer.
- Tension is calculated on equivalent span=Sqroot of ( sigmaL3/sigmaL)

( $\mathrm{L}$ is individual spans) Tension is given from Sag Tension chart and sag is checked in last span. 


\section{CONCLUSION}

\section{Earthing of Towers}

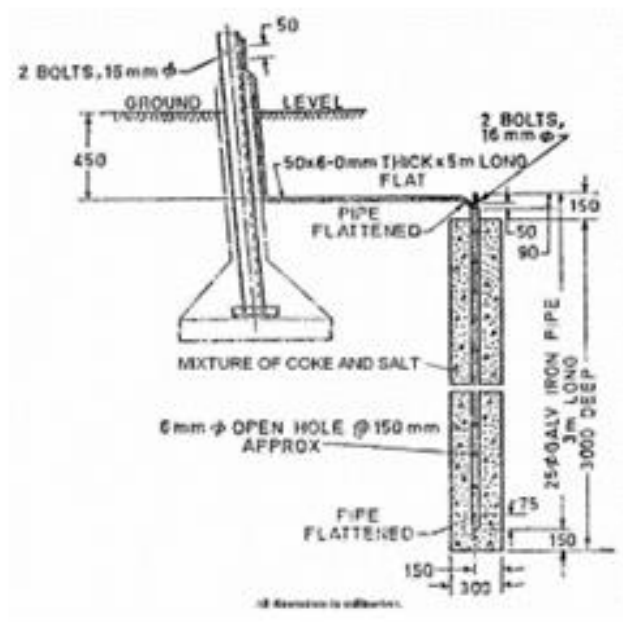

Fig 11

- Tower footing resistance is to be maintained as less than $10 \mathrm{ohm}$.

- Two types of earthing is done for towers:

$\checkmark$ Pipe type if soil is normal as per IS 5613/IS 3043 in Leg-1 if required Leg-3 also. With $25 \mathrm{mmGI}$ pipe.

$\checkmark$ Counter poise if soil is rocky/FR \$ GI wires from 04 legs $25 \mathrm{mtr}$ each or more if required $(7 / 3.66 \mathrm{~mm})$

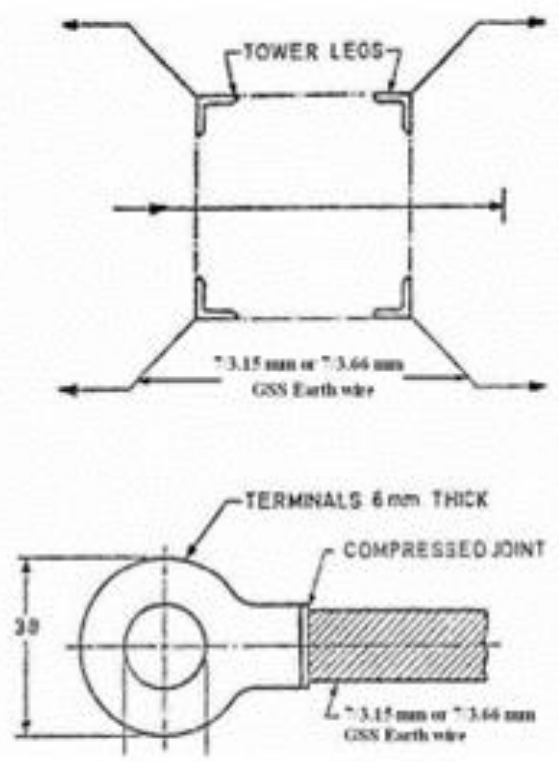

Fig 12

- Fixing of all accessories \& final checking

- To megger of line.

- Charging.
Construction \& erection management of intra country, inter region and international transmission lines are no doubt very tough now a days because of awareness of people, pollical interferences, environment and technical stringent criteria. But it needs prudent people supporting attitude of officials executing the work and support of all stakeholders to complete this very difficult task. The norms of compensation for trees to be felled and standing crops to be damaged and utility of land to be affected need to standardize through deliberation of experienced people of different segments so that the issues can get resolved with less litigation and full satisfaction of all in a collaborative approach with less time. Otherwise generating stations gets ready for commercial operation of plant but due to nonavailability of proper transmission networks plant remains idle which is a mere national waste. Similarly, the people also should carry an impression that the project is for them and for greater befit of nation so it is also their duty to come to an agreeable solution without becoming much greedy. Government norms also should finalize with positive approach with a view to bring the project faster with supportive approach to affected people.

\section{REFERENCES}

[1]. Construction manual of Rajasthan TRANSCO

[2]. Construction manual of AP TRANSCO

[3]. Internet

[4]. Self-work Experience 